\title{
Numerical Simulation of the Influence of the Distance between the Diamond Sawblade and Free Surface on Cutting Performance
}

\author{
Qingliang Zeng $\mathbb{D}^{1},{ }^{1,2}$ Zhiwen Wang $\mathbb{D}^{1},{ }^{1}$ Zhenguo Lu $\mathbb{D}^{\circ},{ }^{3}$ Lirong Wan $\mathbb{D}^{1},{ }^{1}$ and Xin Zhang ${ }^{1}$ \\ ${ }^{1}$ College of Mechanical and Electronic Engineering, Shandong University of Science and Technology, Qingdao 266590, China \\ ${ }^{2}$ College of Information Science and Engineering, Shandong Normal University, Jinan 250358, China \\ ${ }^{3}$ College of Transportation, Shandong University of Science and Technology, Qingdao 266590, China
}

Correspondence should be addressed to Zhiwen Wang; zwwang2016@outlook.com

Received 28 April 2021; Revised 27 July 2021; Accepted 14 August 2021; Published 18 August 2021

Academic Editor: Jiang Jin

Copyright (c) 2021 Qingliang Zeng et al. This is an open access article distributed under the Creative Commons Attribution License, which permits unrestricted use, distribution, and reproduction in any medium, provided the original work is properly cited.

\begin{abstract}
The diamond sawblade has been widely used in the field of rock mining and processing. This article, through the establishment of a numerical simulation model of diamond sawblade cutting rock, studies the influence of the distance between the diamond sawblade and free surface on cutting performance. In the process of diamond sawblade cutting rock, with the increase of the distance from the sawblade to the free surface, the average cutting force, normal force, and tangential force of the sawblade increase at first and then stabilize, and the axial force gradually decreases and tends to be stable. In the process of cutting rock with fixed depth, cutting force and rock damage are positively related to feed speed and cutting depth of the diamond sawblade. Through the statistical analysis of rock damage by image recognition program statistics, it is concluded that the feed speed and cutting depth of the sawblade have a significant impact on the rock damage value. When the distance increases to $12 \mathrm{~mm}$, there is a relatively complete rock plate between the sawblade and free surface. The rock free surface damage disappears when distance reaches $16 \mathrm{~mm}$. The research results provide a theoretical basis for the sawblade processing rock plate.
\end{abstract}

\section{Introduction}

Rocks are widely used in construction, bridge, and other fields. The mining and processing of rocks have become the important contents of many researchers. The diamond sawblades are the tools mainly used in the rock processing. Many scholars have made tremendous research studies on the process of rock cutting with the diamond sawblade. Xu et al. studied the force ratio of the diamond sawblade in cutting rock with experiments and established the relation equations of rock cutting with the diamond sawblade; the study discovered that with the rotation speed increasing, the force ratio increases linearly but normal force declines sharply and the tangential force keeps constant [1], and they investigated the cutting force and energy consumption of circular saw cutting granite and obtained that the power rises linearly with the plowed surface rising [2]. Yurdakul studied the influence of the cutting mode and feed rate on cutting efficiency and cutting amount; the investigation found that the cutting consumption of the down-cutting mode is less by valuing the sawblade cutting large rock [3], as well as the relations between cutting specific energy consumption and cutting parameters [4]. Ersoy discussed the relations between rock types and cutting specific energy consumption by using the multiple linear regression analysis to build the relationship between specific cutting energy of the rock properties and cutting parameters [5]. Guney, based on the rock surface hardness test, established the prediction model of large diameter circular sawblade sawability about cutting carbonate rocks [6]. Buyuksagis studied the influence of diamond saw segment characteristics on cutting performance and built the predict function about the specific energy with simple rock property test procedures [7] and the cutting parameters on cutting specific energy consumption wear by the experiments [8]. 
The sawblade is a typical high-speed rotating thin plate, which is prone to vibration in the action working condition [9]. The sawblade vibrates due to the cutting force in the operation, and the sawblade vibration rises with the increasing cutting force, which causes that the sawblade wear faster and shortens its service life [10]. Chang and Chen researched the sawblade cutting force effect on vibration and optimized the sawblade parameters [11]. Krolczyk introduced the disc chipper balancing process in its own bearing and disc chipper repairing technology [12]. The wear is an important factor that affects the service life and performance of the saw blade. Many experts have studied the wear of the sawblade in the process of rock cutting. Konstanty proposed a theoretical model of natural stone sawing, proved that the rock processing is the multidimensional problem [13], and studied the segment wear during granite cutting revealing the matrix wear complexity [14]. Ilio presented a theoretical model of tool wear and verified the theoretical model with the experimental results with the empirical experiment due to the tool wear complexity [15]. Wei established a fuzzy sorting system and a rock saw ability classification model based on fuzzy mathematics, where only the rock phase analysis and mechanical property test are needed to select the proper sawblade and cutting parameters [16]. Ersoy, based on the multiple regression analysis with the laboratory test results, studied the performance of the diamond sawblade and analyzed the influence of cutting parameters on the wear mechanism of the diamond sawblade [17]. Xu analyzed the effect of temperature on the wear of the diamond sawblade and the bonding mechanism of Ti/Crcoated diamond with iron matrix and designed the different structural segments sawblade and optimize parameters [18]. Buyuksagis studied the relationship between specific energy consumption of the sawblade and specific wear rate and combined the thermal wear mechanisms to decline thermal wear by applying Ti/Cr-coated diamonds [19]. At the same time, some researchers also studied the cutting performance of the diamond sawblade. Unver, on the basis of regression analysis, established the prediction equation of rock sawability [20]. Delgado et al. studied the influence of rock microhardness on the sawing performance of Pink Porrino granite through the rock cutting test [21].

In the rock occurs damage and crack formation under the action of the cutting tools. And some scholars have studied the damage and failure of rock. Peng et al. summarized the detection technology of rock damage and introduced the image processing and fractal theory, directly calculating the damage variable based on the image [22]. Xie confirmed that energy has a great influence on rock deformation and failure through theoretical and experimental research studies, and the strain energy released breaking the rock structural failure [23]. Steffler simulated large-scale geological characteristics by using laboratory scale experiments and studied the energy distribution of cracks under compression and shear [24]. Zhang discussed the definition of damage variable from microscopic and macroscopic aspects and studied the evolution of damage equation [25]. Ge carried out an experimental study on damage mechanics of rock and soil [26]. Zeng established a numerical simulation model of rock damage caused by diamond sawblade cutting, according to the brittle materials mechanism research, the cutting parameters influence rock damage [27]. Wang researched the sawblade cutting parameters influence on cutting force and cutting energy consumption and the rock damage with the numerical simulation method [28].

There are many studies about the diamond sawblade and the rock damage and the cutting force with the circular sawblade cutting. However, there is less research about the influence of free surface influence on the diamond sawblade cutting rock. The numerical simulation method is more efficient and cheaper than experiments. This study, on the basis of a numerical simulation model for cutting rock with the diamond sawblade, aims to study the influence of the distance between the free surface and diamond sawblade on cutting performance. In addition, it has investigated the effects of feed speed, cutting depth, and distance between the free surface and diamond sawblade on cutting force and rock damage.

\section{Quantitative Method of Rock Damage Based on Image Recognition}

Based on $\mathrm{C}$ language image recognition program, this study carries out the quantitative analysis of the statistical analysis of rock damage. The flow chart of the program is shown in Figure 1(a). To start with, the damage nephogram of the rock to be identified is imported into the program. The program records the number of imported program pictures, stores the pictures into the image array, and inputs the damage value corresponding to the legend color. And then, the program identifies and counts the pixels of rock damage nephogram one by one and accurately records the number and total number of pixels with the same color as the damage legend. After each image is identified, it is judged whether all the pictures have been identified. After all, the recognition is completed, and the results will be output to end the program; if not, return to continue to be identified. In order to improve the accuracy of identification and avoid the influence of the size of rock damage nephogram on the results, the ratio of different color pixels to the total number of pixels within the rock boundary is used to represent the different damage amounts of rock. In addition, the symmetry plane of the sawblade perpendicular to the axis of the sawblade is selected as the rock damage nephogram to be identified, and the cumulative sum of the proportion of various pixels and the damage value is defined as the rock damage value so as to improve the efficiency of image recognition.

The program interface is shown in Figure 1(b). The first step is to start the program and click the button "Import Pictures." And then, the rock damage nephogram is imported to be analyzed, and multiple images can be selected at the same time. After inputting the corresponding damage value of each color in the legend, the next step is to click the button "Analysis" to start the program automatic analysis module, analyzing the pictures one by one. After the analysis is completed, the software makes statistics on the various 


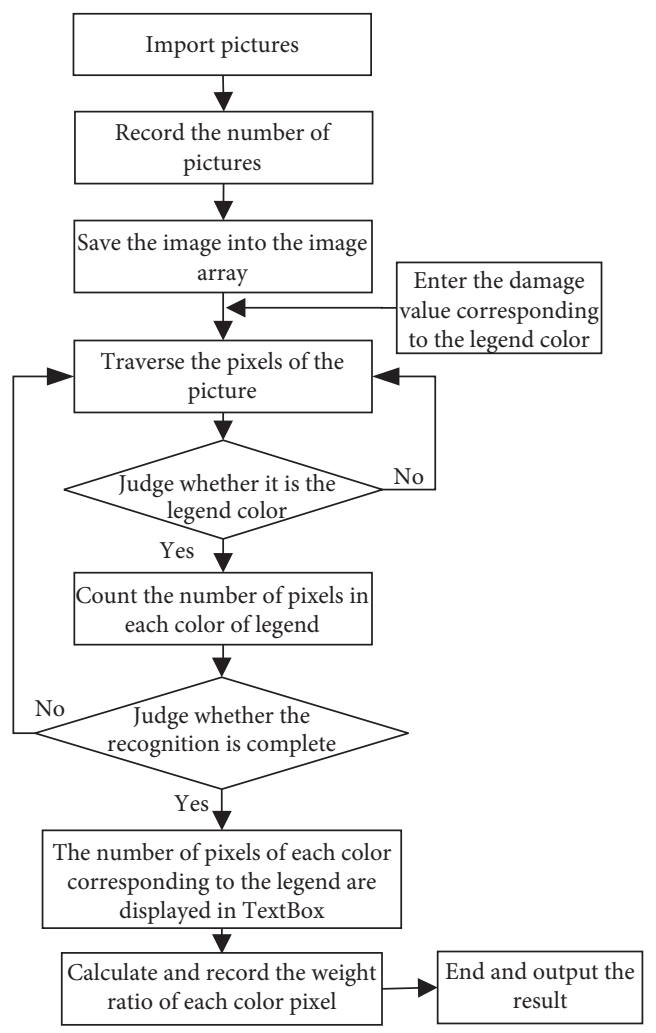

(a)

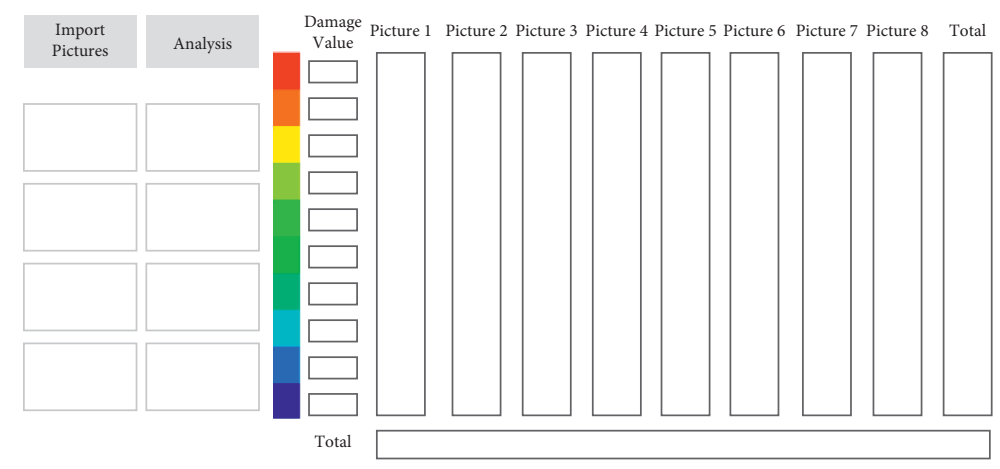

(b)

FIGURE 1: Flowchart of image recognition program and the interface of rock damage image recognition program.

pixels of the image to get the results, and the software analysis and calculation results are displayed in the program interface.

\section{Numerical Simulation Model}

3.1. The Building of the Simulation Model. The study establishes the 3D structure model of rock cutting with the diamond sawblade by using SolidWorks and the numerical model of rock cutting by the diamond sawblade by importing ANSYS/LS-DYNA, as shown in Figure 2. The diameter of the diamond sawblade is defined as $380 \mathrm{~mm}$. The diamond sawblade has 24 segments $(15 \mathrm{~mm}$ high, $3.4 \mathrm{~mm}$ thick, and $40 \mathrm{~mm}$ long), and the rock is a cuboid of $800 \times 150 \times 125 \mathrm{~mm}$. Based on the research of the rock cutting process with the diamond sawblade, this study focuses on rock damage, defines rock material as MAT_RHT, and regards MAT_RIGID material as the diamond sawblade. A grid SOLID164 with 8 nodes of 6 facets is used to divide rock and diamond sawblades, as shown in Figure 2. The key material parameters of MAT_RHT are given in Table 1. By adding constraints to the simulation model of cutting rock with the diamond sawblade, full constraint on rock bottom, Y-direction displacement constraint is applied to the left and right surfaces of rock, $X$-direction displacement constraint is applied to the front and back surfaces of rock, and nonreflecting boundaries are added to the noncutting surface of rock to achieve the effect of simulating large volume rock mass with the small rock model. In addition, the $X$ and $Y$ axes rotation constraints and $X$ and $Z$ direction displacement constraints are applied to the numerical simulation model of diamond sawblade cutting rock.

The contact between the diamond sawblade and rock is defined as eroding surface and surface and automatic general. In addition, it is necessary to control the energy of hourglass and prevent negative volume in order to improve the accuracy of numerical simulation. In the numerical model of cutting rock with the diamond sawblade, the feed speed of the diamond sawblade is $0.20,0.3$, and $0.4 \mathrm{~m} / \mathrm{min}$, the rotating speed is $3000 \mathrm{r} / \mathrm{min}$, and the distance between the diamond sawblade and free surface is $4,8,12,16,20$, and $30 \mathrm{~mm}$, respectively.

3.2. Correction and Verification. In this study, the parameters of the rock model are corrected by using the method of the numerical simulation uniaxial compression test. The uniaxial compression test is carried out on a standard cylinder specimen by the uniaxial compression test bench to obtain the mechanical properties parameters of rock samples and calibrate the numerical model. The uniaxial compression test of rock is simulated by the numerical simulation method, and the mechanical parameters of rock sample are calibrated on the basis of the stress-strain curve of rock sample and the fragmentation of rock sample. A cylinder with a diameter of $50 \mathrm{~mm}$ and a height of $100 \mathrm{~mm}$ is selected for the uniaxial compression test. 


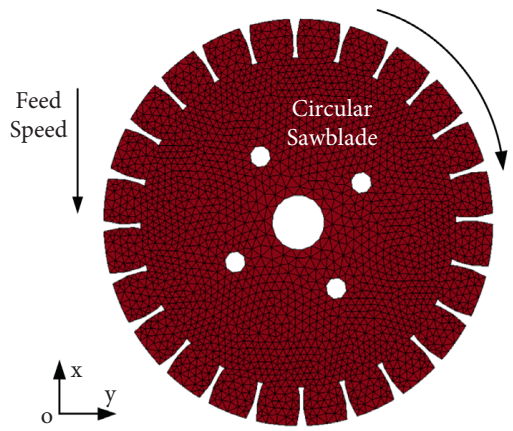

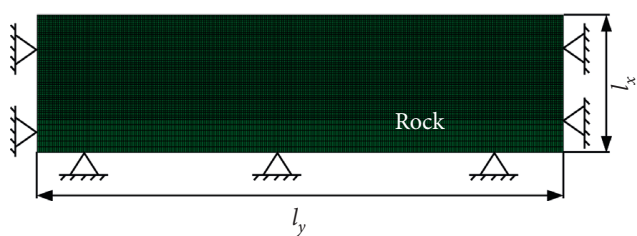

(a)

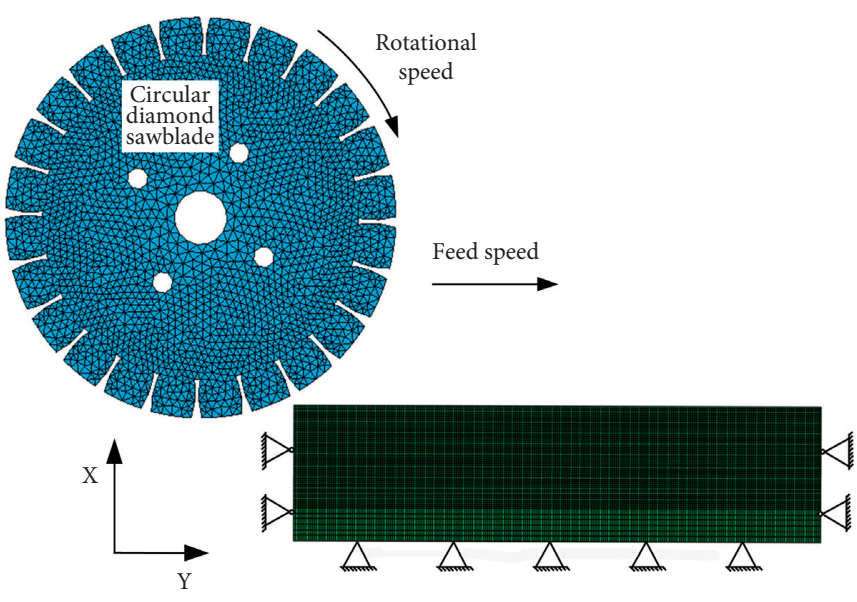

(b)

Figure 2: Numerical simulation model of rock cutting with the diamond sawblade. (a) Vertical cutting rock model with the diamond sawblade., (b) Rock cutting model with fixed depth of the diamond sawblade.

TABLE 1: Key performance parameters of rock.

\begin{tabular}{lccccc}
\hline Parameters & Yang's modulus $(\mathrm{GPa})$ & Shear limit $(\mathrm{MPa})$ & Tension limit $(\mathrm{MPa})$ & Passion ratio & Mass \\
\hline Value & 5.7 & 0.24 & 23 & 0.23 & $2.9 E 3 \mathrm{~kg} / \mathrm{m}^{3}$ \\
\hline
\end{tabular}

A cylinder with a diameter of $50 \mathrm{~mm}$ and a height of $100 \mathrm{~mm}$ is used for numerical simulation, which is the same as that of the uniaxial compression test specimen, as is shown in Figure 3(a). The numerical simulation model uses two rigid plates to compress the cylindrical model. The lower plate is fully constrained, and the upper rigid plate moves downward at a uniform speed of $5 \mathrm{~mm} / \mathrm{s}$ so as to realize quasistatic loading. The results show that the simulation curve is in good agreement with the test curve, and the uniaxial compression results of numerical simulation are similar to the test results, which leads to the fracture of rock samples, as shown in Figures 3(b) and 33(c).

The axial stress-strain curve obtained by numerical simulation is basically consistent with the laboratory results, as is shown in Figure 3(d). However, the fluctuation of numerical simulation is larger than that of laboratory, which is the wave of the cylindrical rock element model due to compression failure. Generally speaking, the mechanical properties and fracture behavior of materials can be well approximated by numerical models. Therefore, the following models are considered to be effective after correction.

\section{Results and Discussion}

4.1. Process of Diamond Sawblade Cutting into Rock. The diamond sawblade, with rotation speed of $3000 \mathrm{r} / \mathrm{min}$ and feeding speed of $0.3 \mathrm{~m} / \mathrm{min}$, vertically cuts into the rock $4 \mathrm{~mm}$ away parallel to the free surface, with the numerical simulation results shown in Figure 4. In the process of the sawblade cutting into the rock vertically, when the sawblade just contacts the rock, the upper surface (cutting surface) of the rock is damaged due to the extrusion and tensile effect of the sawblade on the rock. Because the sawblade has just contacted the rock, the damage range to the rock is small and has not yet extended to the free surface, as is shown in Figure 4(a). The sawblade continues to cut the rock, and the rock is damaged and broken under the joint action of the sawblade extrusion, tension, and shear. With the increase of cutting depth of the sawblade, the damage range of rock increases and extends to the free surface, as shown in Figure 4(b). The rock damage between the sawblade and the free surface is serious when the sawblade continues to cut the rock, and the rock between the sawblade and the free surface begins to break. The rock damage on the free surface is not evenly distributed along the cutting arc of the sawblade, the rock damage increases gradually along the rotation direction of the sawblade, and the damage area at the cutting position is obviously smaller than the cutting position of the sawblade, as is shown in Figure 4(c). The diamond sawblade continues to cut the rock. The rock near the free surface of the sawblade is more seriously damaged than the side far away from the free surface, and most of the rock units reach the damage limit failure, so there is no rock plate on the side near the free surface of the sawblade, as is shown in Figure 4(d). In the process of diamond sawblade cutting into rock vertically, the range of rock damage and fracture gradually enlarges with the increase of cutting depth.

By analyzing the rock damage cloud, the rock damage area is affected by the sawblade cutting. As the sawblade contacts the rock, the rock occurs the rock damage with the sawblade extrusion and stretching. With the sawblade 


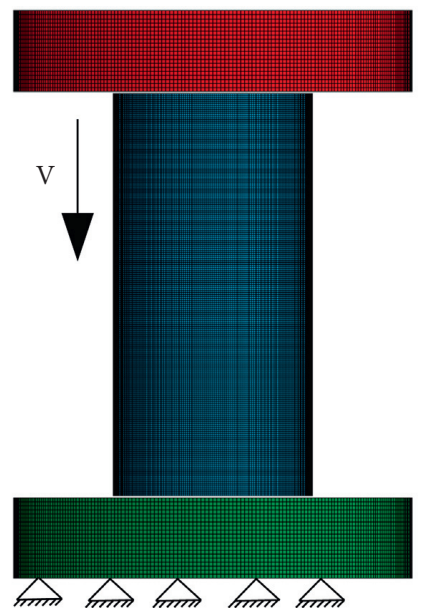

(a)

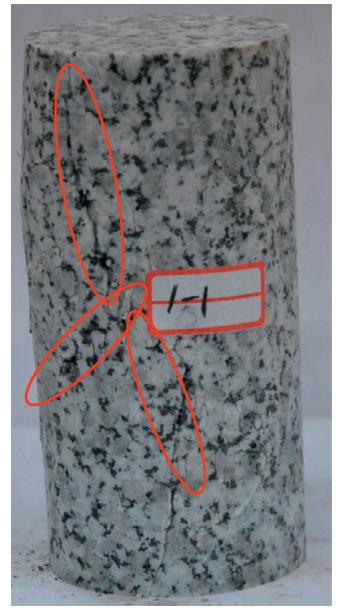

(b)

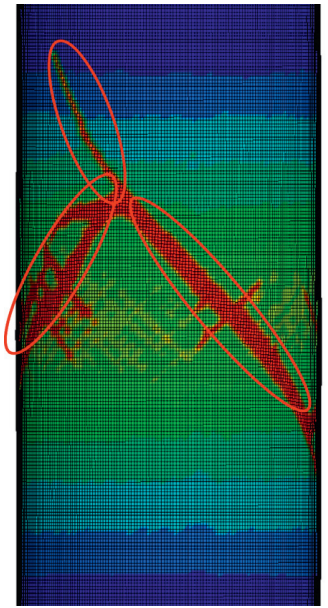

(c)

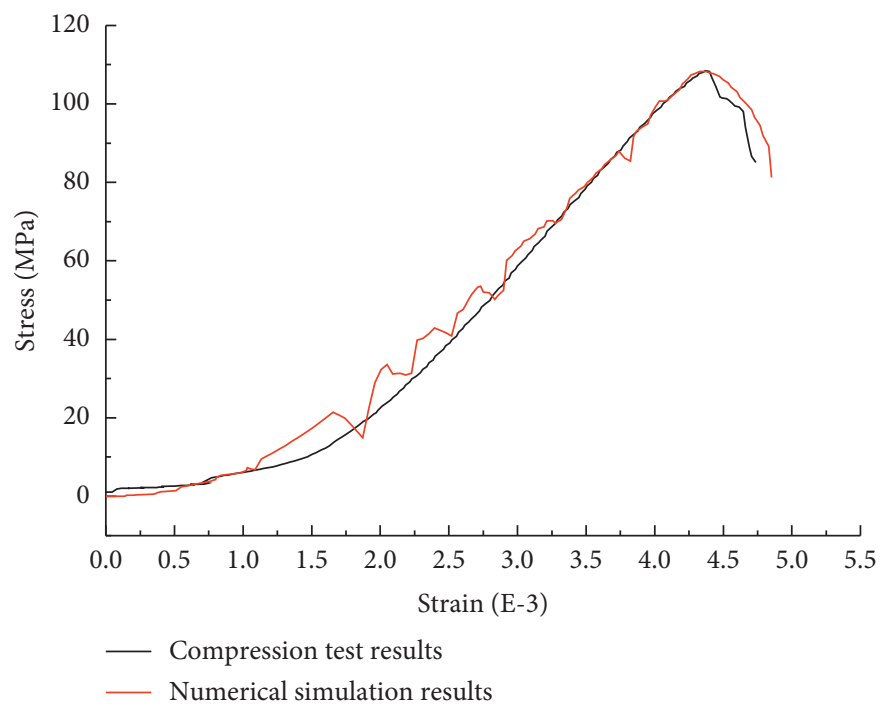

(d)

Figure 3: Uniaxial compression test. (a) Numerical simulation uniaxial compression test. (b) Uniaxial compression test results. (c) Numerical simulation uniaxial compression test results. (d) Uniaxial compression test and numerical simulation of stress-strain curves.

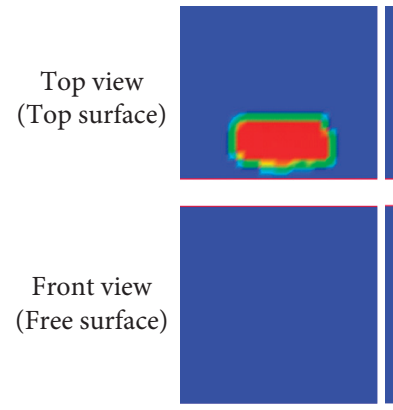

(a)
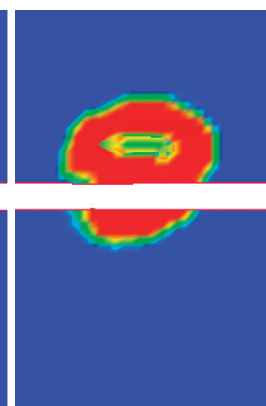

(b)
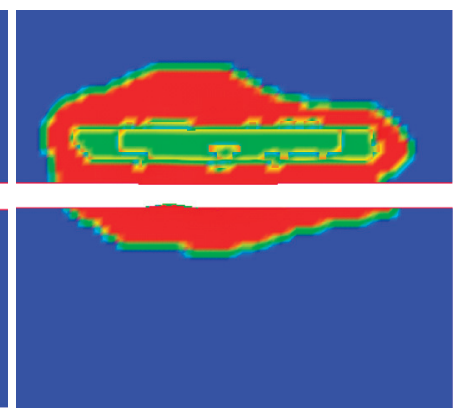

(c)
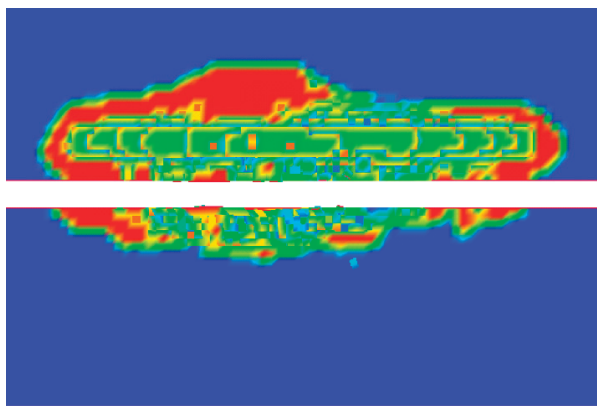

(d)

FIGURE 4: Rock damage nephogram of sawblade cutting into rock vertically.

continuing to cutting, rock damage area rises and some rock elements fail, as plotted in Figure 4(b). And the rock damage depth of the cut-in point is smaller than that of the cut-out, as shown in Figures 4(b) and 4(c) front view, which is caused by the sawblade rotation. The rotating sawblade acts on the rock, forming shear and compression on the rock along the sawblade tangent speed direction. Under the compression action, the rock creep leads to the obvious rise of the damage area and damage depth near the cut-out area of the sawblade. Some rock elements fail with the sawblade cutting. With the 
sawblade compressing and cutting the rock, the rock damage area extends to both sides, and the cut-out area damage width is larger than that of the cut-in area. When the rock damage area width is larger than the distance between the sawblade and the free surface, the rock damage extends to the free surface, plotted in Figures 4(b) and 4(c). With the cutting depth rising, the rock damage width increases. Meanwhile, the rock between the sawblade and the free surface breaks, and there is no rock plate forming.

4.1.1. Influence of Distance between the Sawblade and Free Surface on Cutting Force. In the process of diamond sawblade cutting into rock vertically, the distance between the sawblade and free surface has a great influence on the cutting force. The cutting force of the numerical simulation results of the sawblade vertically cutting into the rock is shown in Figure 5. With the increase of the distance, the cutting force, normal force, and tangential force of the sawblade gradually increase and then tend to be stable, but the axial force decreases at first and then tends to be stable with the increase of the distance. While the distance between the sawblade and the free surface is $4 \mathrm{~mm}$, the average cutting force, normal force, and the tangential force are the smallest, but the average axial force value of the sawblade is the largest. When the distance from the diamond sawblade to rock free surface reaches $12 \mathrm{~mm}$, the average cutting force, normal force, tangential force, and the axial force tend to be stable. The diamond sawblade average forces rise with the increasing feed rate. The change of the cutting force is similar to that of the normal force. The tangential force is more sensitive to the distance from the blade to the free surface than the cutting force and normal force, and the response to the change of the distance is obvious. The feed rate has a significant effect on the cutting force. The higher the feed rate is, the higher the average cutting force, normal force, tangential force, and axial force of the sawblade are, with obvious degree of increase.

In the process of the sawblade cutting into the rock vertically, the rock stress distribution is shown in Figure 6. From the stress distribution diagram of rock, it can be seen that the stress is symmetrically distributed about the sawblade. However, the stress in the plane of the sawblade is not uniformly distributed along the cutting arc of the sawblade, and the maximum stress occurs in the middle of the cutting arc, which is offset by a certain distance along the rotation direction, and the stress at the position where the sawblade cuts into the rock is obviously less than that at the cutting out position of the sawblade. If the distance between the sawblade and the free surface is rather short, the stress distribution of the rock is difficult to be symmetrical with respect to the sawblade. The stress of the rock near the free surface is higher than that of the side far away from the free surface, which leads to the rock between the sawblade and the free surface easy to be broken and difficult to form a complete rock plate. As the distance between the sawblade and the free surface increases gradually, the stress concentration degree of the rock between the sawblade and the free surface is weakened, and the rock is not easy to be broken, resulting in the obvious increase of the cutting force of the sawblade. When the distance between the sawblade and the free surface is short, the stress distribution of the rock is not symmetrical with respect to the sawblade, and the axial force of the sawblade is inclined to the side of the free surface, especially when the rock between the sawblade and the free surface is broken, the asymmetry of the axial force of the sawblade is enhanced, and the axial force of the sawblade is larger; when the distance between the sawblade and the free surface is larger, the rock stress distribution restores to the plane symmetry of the sawblade and the axial force of the sawblade is smaller.

In the process of diamond sawblade cutting into rock parallel to the free surface, when the distance between the sawblade and the free surface is relatively close, the stress concentration of the rock near the free surface of the sawblade leads to the reduction of its bearing capacity. In this case, the rock is easy to reach the damage failure standard, i.e., the rock fracture failure, so it is difficult to form a complete rock plate between the sawblade and the free surface of the rock. With the increase of the distance from the sawblade to the free surface, the stress concentration degree decreases, the rock stress bearing capacity increases gradually, and the cutting force of the sawblade increases obviously; and when the distance between the sawblade and the free surface reaches a certain value, a relatively complete rock plate is formed between the sawblade and the free surface, and the cutting force of the sawblade reaches a relatively stable value. The bearing capacity of the rock between the sawblade and the free surface is greatly affected by the distance between the sawblade and the free surface. Therefore, with the increase of the distance from the sawblade to the free surface, the average cutting force, tangential force, and normal force of the sawblade increase obviously and then reach a stable value. The average axial force of the sawblade is expressed by the average value of the absolute value of the axial force. When the distance between the sawblade and the free surface is relatively close, the rock between the sawblade and the free surface is easy to be broken, and the side near the free surface of the sawblade and the rock on the side of the nonfree surface are relatively large, that is, the axial force on both sides of the sawblade is asymmetric, resulting in a large average axial force of the sawblade. When the distance between the sawblade and the free surface increases to a certain value, a relatively complete rock plate is formed between the sawblade and the free surface. The extrusion between the sawblade and the rock on both sides can offset each other to a certain extent, and the average axial force of the sawblade decreases and remains stable.

4.1.2. Influence of Distance between the Sawblade and Rock Free Surface on Rock Damage. If the sawblade cuts the rock, the rock inelastic deformation will gradually form the rock damage. Compression, tension, shear, and other forces act on the rock, resulting in inelastic deformation and rock damage. The greater the force of the sawblade acting on the rock, the greater the damage value of the rock. When the damage value of rock element reaches 1 , the failure of rock 


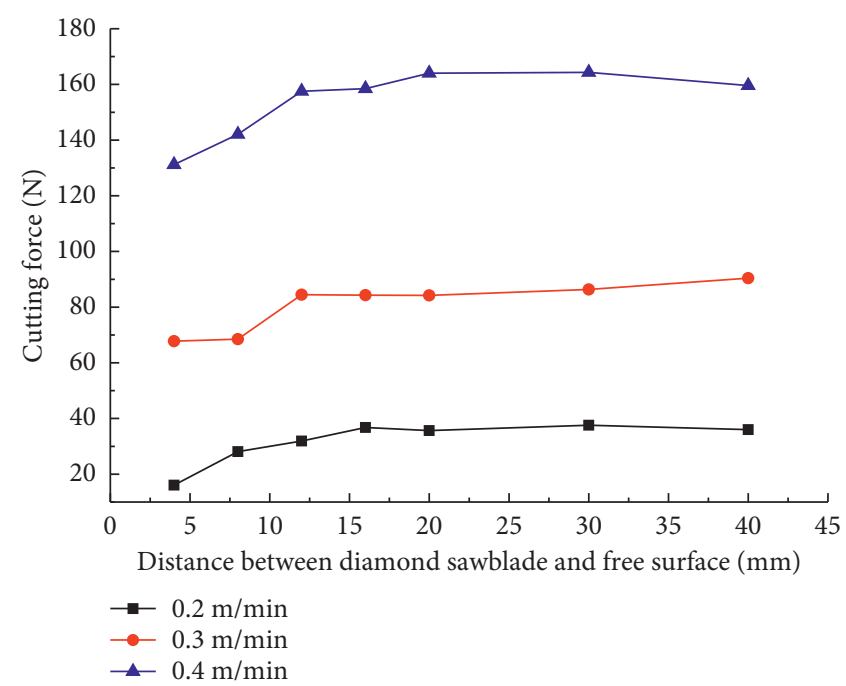

(a)

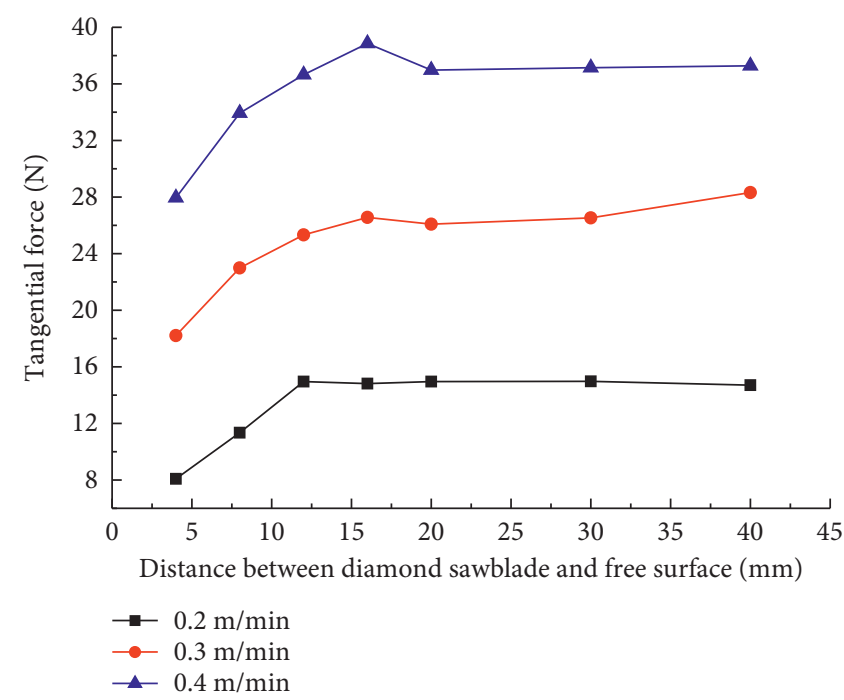

(c)

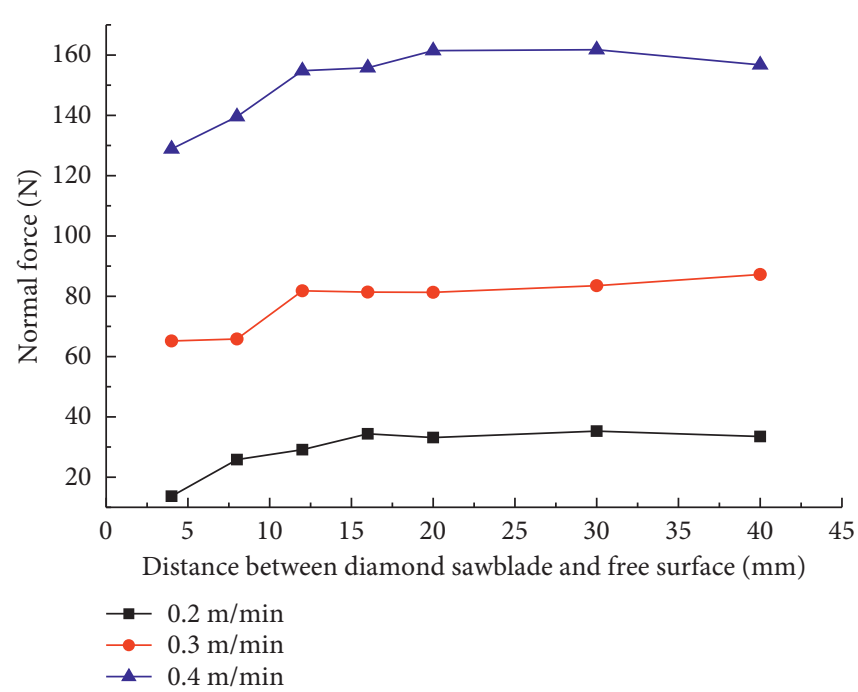

(b)

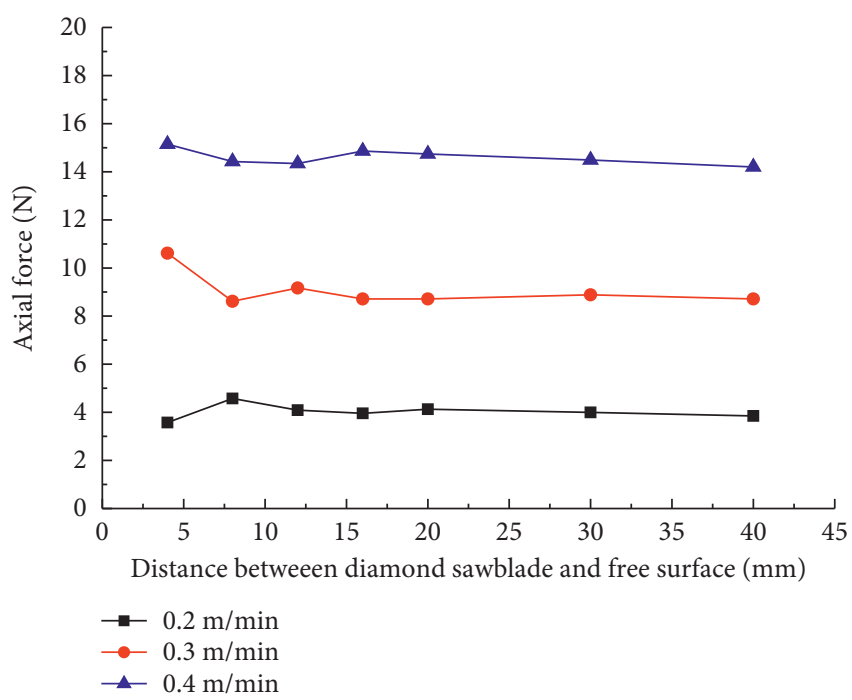

(d)

FIGURE 5: Vertical cutting force of the diamond sawblade into rock and variation curve of distance between the sawblade and rock free surface. (a) Variation curve of average cutting force and distance between the sawblade and free surface. (b) Variation curve between average normal force and distance between the sawblade and rock free surface. (c) Variation curve between average tangential force and distance between the sawblade and free surface. (d) Variation curve between the average axial force and sawblade to rock free surface.

element is deleted. As is shown in Figure 7 of the rock damage cloud, the sawblade cuts into the rock at the cutting speed of $0.3 \mathrm{~m} / \mathrm{min}$, the rotation speed of $3000 \mathrm{r} / \mathrm{min}$, and the distance from the free surface is $4,8,12,16,20$, and $30 \mathrm{~mm}$, respectively. From the damage nephogram, it can be concluded that the distance from the sawblade to the free surface has a great influence on the rock damage. When it is a short distance between the sawblade and the free surface, the failure of the rock element between the sawblade and the free surface is deleted. When the distance increases to $12 \mathrm{~mm}$, a relatively complete rock plate is formed between the sawblade and the free surface. With the increase of the distance from the sawblade to the free surface, the damage range of the free surface gradually decreases. When the distance reaches $16 \mathrm{~mm}$, the damage area of the rock free surface disappears basically. Through the comparative analysis of the rock damage of different distances from the sawblade to the free surface, it is obvious that the different distance between the sawblade and the free surface has a greater impact on the rock damage. When the distance is 4 and $8 \mathrm{~mm}$, there is no complete rock plate between the sawblade and the free surface; when the distance reaches $12 \mathrm{~mm}$, a relatively complete rock plate is formed between the sawblade and the free surface. With the continuous increase of the distance between the sawblade and the free surface, the thickness of the rock plate formed by sawing is also increasing. With the increase of the distance from the free surface, the rock debris increases at first and then decreases, maintaining a relatively stable state.

The image recognition program identifies the diamond sawblade with the same rotation speed and different feed speeds and then quantitatively analyzes the 


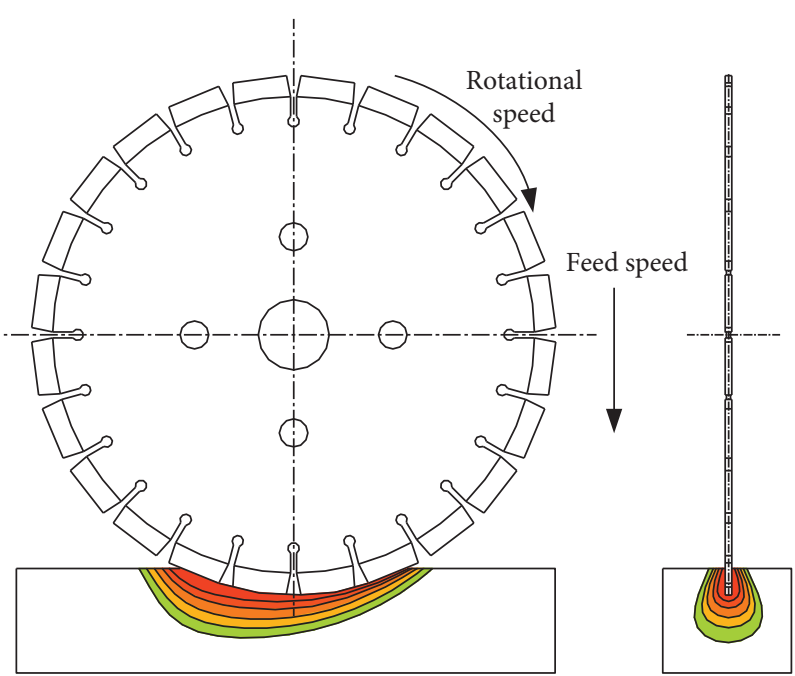

Figure 6: Stress distribution in the process of the diamond sawblade cutting into rock.

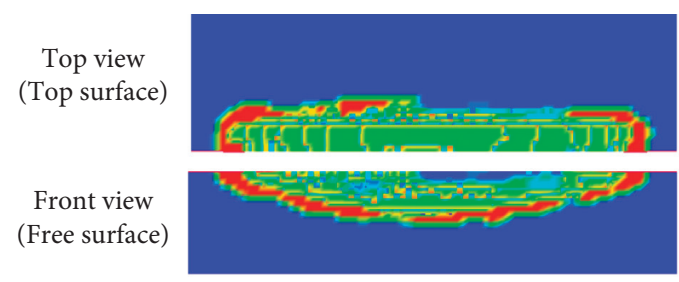

(a)

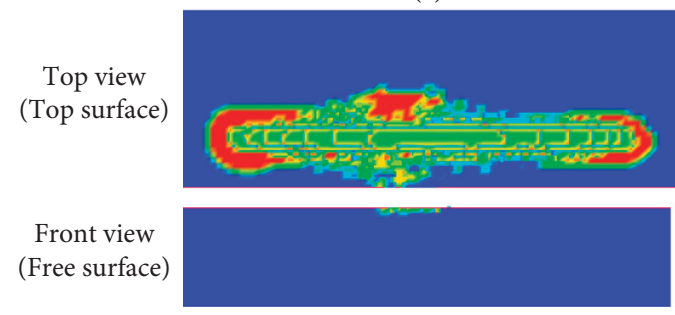

(d)
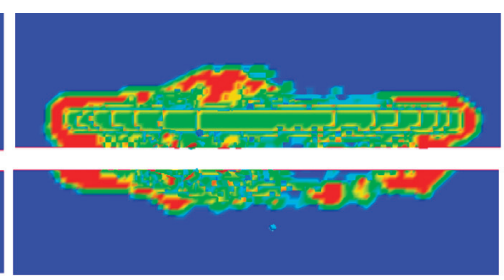

(b)

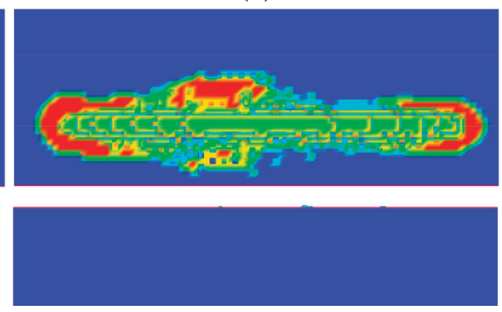

(e)

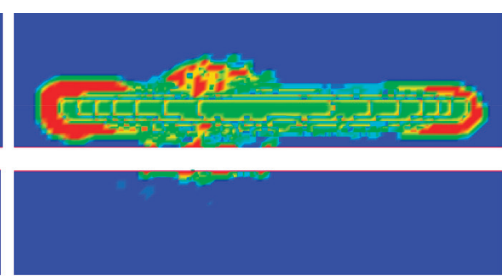

(c)

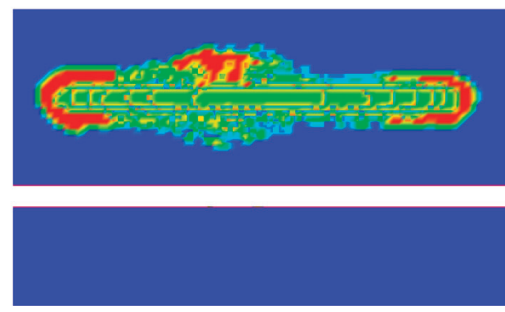

(f)

FIgURE 7: Damage nephogram of sawblade cutting vertically into rock at different distances from free surface of rock.

rock damage on the basis of the rock damage nephogram at different distances from the free surface. The image recognition program is used to analyze the rock damage nephogram and quantify the rock damage. The curve of the relationship between the rock damage value and the distance between the sawblade and the free surface is shown in Figure 8. The damage value of rock decreases with the increase of distance. When the distance between the sawblade and the free surface reaches $20 \mathrm{~mm}$, a turning point appears in the change of the rock damage value, and the rock damage value tends to be stable. With the increase of the distance between the sawblade and the free surface, the influence on rock damage decreases significantly, and the change trend of the rock damage value is consistent with the rock fragmentation trend. The feed rate of the diamond sawblade has an obvious influence on the rock damage value. In the curve of the relationship between the rock damage value and the distance between the sawblade and the free surface, it is obvious that the rock damage value is positively correlated with the feed rate of the sawblade, compared with the rock damage values of the same distance and different feed rates.

4.2. The Process of Diamond Sawblade Cutting Rock with Constant Depth. The diamond sawblade, with cutting depth of $8 \mathrm{~mm}$, feeding speed of $0.30 \mathrm{~m} / \mathrm{min}$, and rotation speed of $3000 \mathrm{r} / \mathrm{min}$, cuts into the rock $8 \mathrm{~mm}$ away from the free surface, with the numerical simulation results shown in Figure 9. When the sawblade contacts the rock, the rock damage appears in front of the cutting direction of the diamond sawblade. The damage area is basically symmetrical with respect to the sawblade, and the damage extends to the free surface, as shown in Figure 9(a); when the diamond sawblade further cuts the rock, the damage of the rock presents obvious asymmetry, and with the increase of the cutting distance of the sawblade, the damage area of the free surface increases obviously, as is shown in Figures 9(b)-9(d). In the process of cutting rock with the diamond sawblade, the heterogeneity of rock and the 


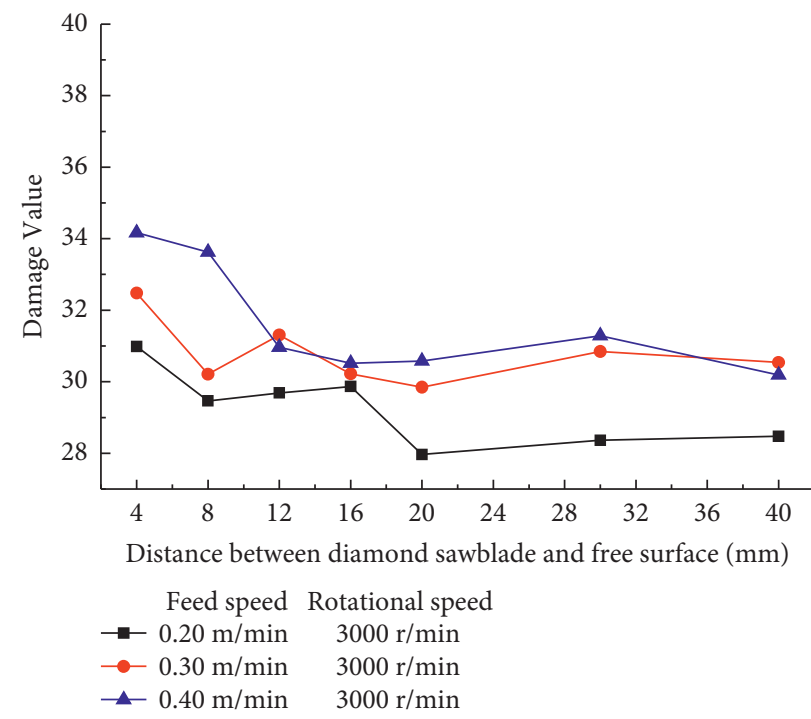

FIGURE 8: Variation curve of the rock damage value and distance between the sawblade and rock free surface.

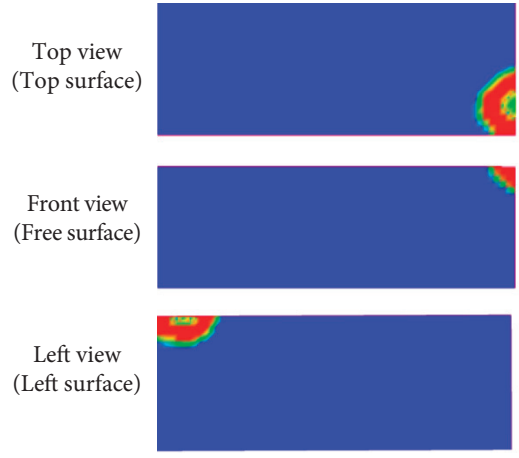

(a)
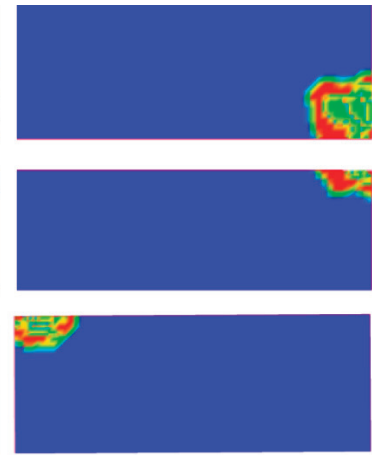

(b)
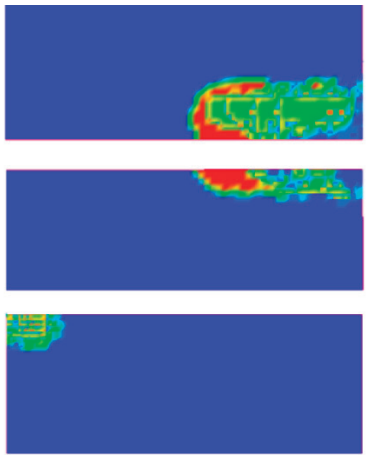

(c)
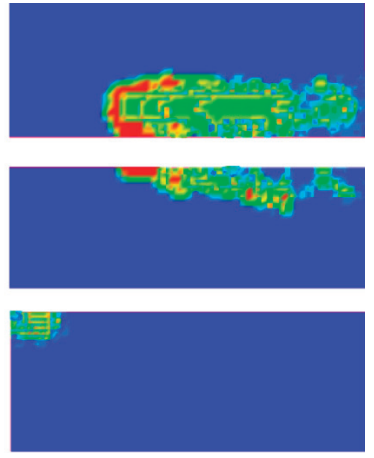

(d)

Figure 9: Damage nephogram of diamond cutting rock at fixed depth.

instability of cutting force are the main reasons for the randomness of rock fragments.

\subsubsection{The Influence of Operation Parameters on Cutting} Force. According to the numerical simulation results of the cutting force of cutting rock with different distances from the sawblade to the free surface parallel to the free surface, it can be clearly seen that the distance from the sawblade to the free surface has a great influence on the average cutting force, normal force, tangential force, and axial force, as shown in Figure 10. With the increase of the distance from the sawblade to the free surface, the average cutting force, normal force, and tangential force of the sawblade increase at first and then stabilize, and the axial force decreases and then stabilizes. When the distance between the sawblade and the free surface is $20 \mathrm{~mm}$, the cutting force, normal force, and tangential force of the sawblade increase with the increase of the distance, and the axial force decreases with the increase of the distance; when the distance is greater than $20 \mathrm{~mm}$, the average cutting force, normal force, tangential force, and axial force of the sawblade are relatively stable.
In the process of cutting rock with fixed depth by the sawblade, the stress diagram of the sawblade acting on the rock is shown in Figure 11. When the sawblade is cutting at a certain depth, the stress distribution is symmetrical with respect to the sawblade, and the nonuniform distribution occurs in the plane of the sawblade. The maximum stress occurs in the middle position of the contact arc between the sawblade and the rock, which deviates a certain distance from the rotation direction. When it is a short distance between the sawblade and the free surface, the stress distribution of the rock presents asymmetry. The stress of the side near the free surface of the sawblade is obviously greater than that of the side far away from the free surface. The rock near the free surface is easy to be broken due to the stress concentration. When the distance between the sawblade and the free surface increases gradually, the rock stress concentration between the sawblade and the free surface weakens, which leads to the improvement of the rock bearing capacity. The cutting force of the sawblade increases with the increase of the distance from the sawblade to the free surface. However, the average axial force of the sawblade is opposite to the average cutting force. When there exists a short distance between the sawblade and the free surface, the rock near the free surface is 


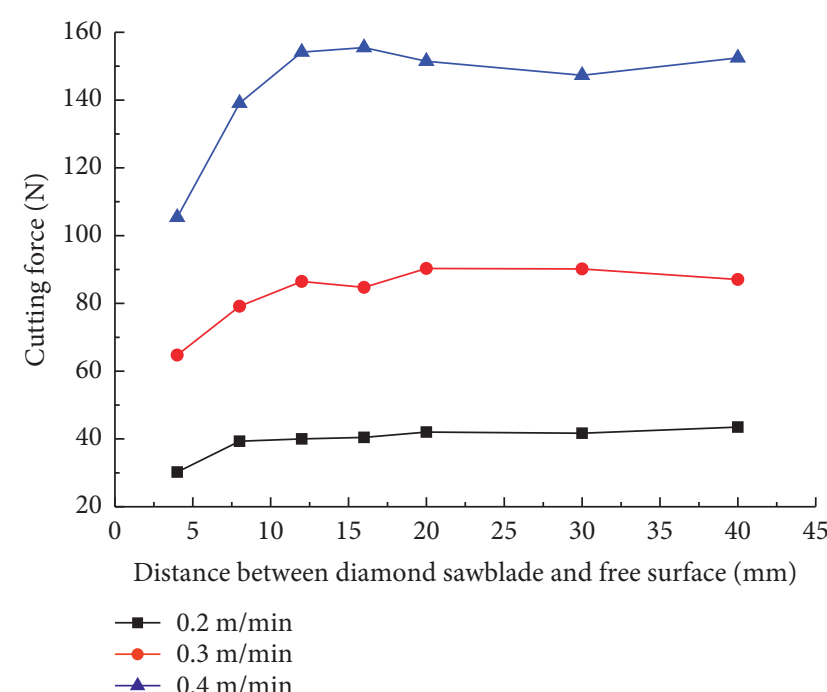

(a)

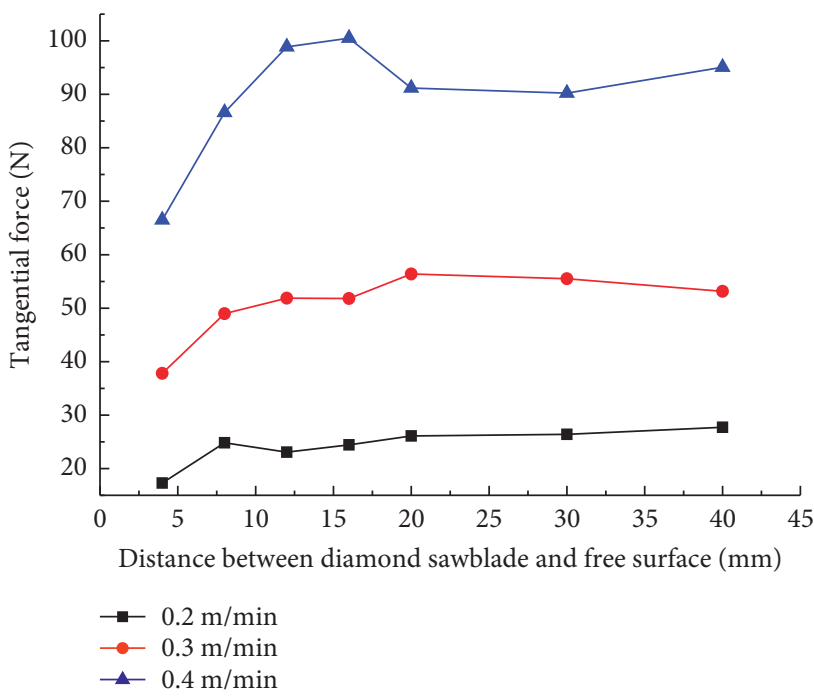

(c)

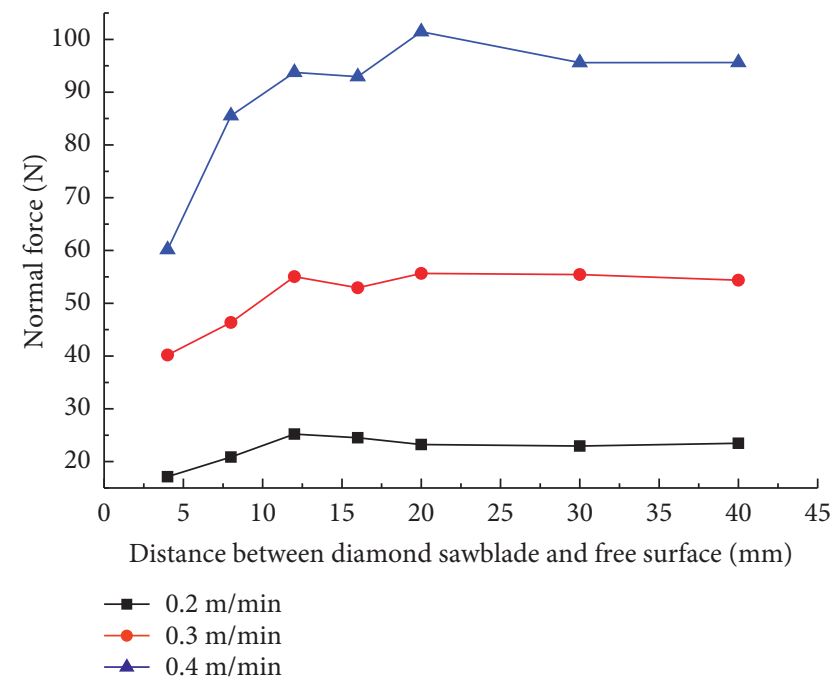

(b)

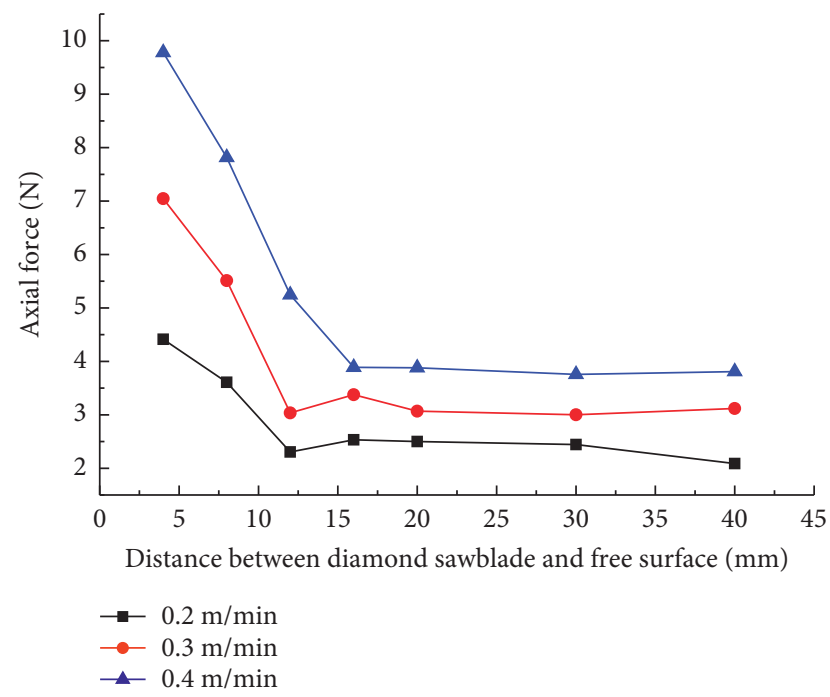

(d)

FIGURE 10: The curves of the force of the diamond sawblade cutting rock at fixed depth and the distance between the sawblade and rock free surface. (a) Variation curve of average cutting force and the distance between the sawblade and free surface. (b) Variation curve between average normal force and distance between the sawblade and rock free surface. (c) Variation curve between average tangential force and distance between the sawblade and free surface. (d) Variation curve between average axial force and the sawblade to rock free surface.

broken, and the axial force between the sawblade and the rock far away from the free surface is significantly greater than that between the sawblade and the rock near the free surface. Therefore, when the distance between the sawblade and the rock near the free surface is relatively small, the axial force of the sawblade is large. With the increase of the distance, the stress distribution on both sides of the sawblade gradually returns to a relatively symmetrical state. In the process of cutting rock, the sawblade interacts with the rock wall on both sides, and the axial force on the sawblade can weaken each other within a certain range.

4.2.2. The Influence of Operation Parameters on Rock Damage. The diamond sawblade, with rotation speed of $3000 \mathrm{r} / \mathrm{min}$, feeding speed of $0.3 \mathrm{~m} / \mathrm{min}$, and cutting depth of $8 \mathrm{~mm}$, cuts into the rock $4,8,12,16,20$, and $30 \mathrm{~mm}$ away, respectively, to the free surface, with the numerical simulation results shown in Figure 12, showing that the distance between the sawblade and the free surface has a great influence on the damage and breakage of rock. The numerical simulation results show that when there exists a short distance between the sawblade and the free surface, it is difficult to formulate a rock plate between the sawblade and the free surface, and the damage range of the rock extends to the free surface. However, with the increase of the distance from the sawblade to the free surface, the rock damage range gradually widens. The turning point occurs when the distance between the sawblade and the free surface is $20 \mathrm{~mm}$. With the increase of the distance, the thickness of the rock plate between the sawblade and the free surface 


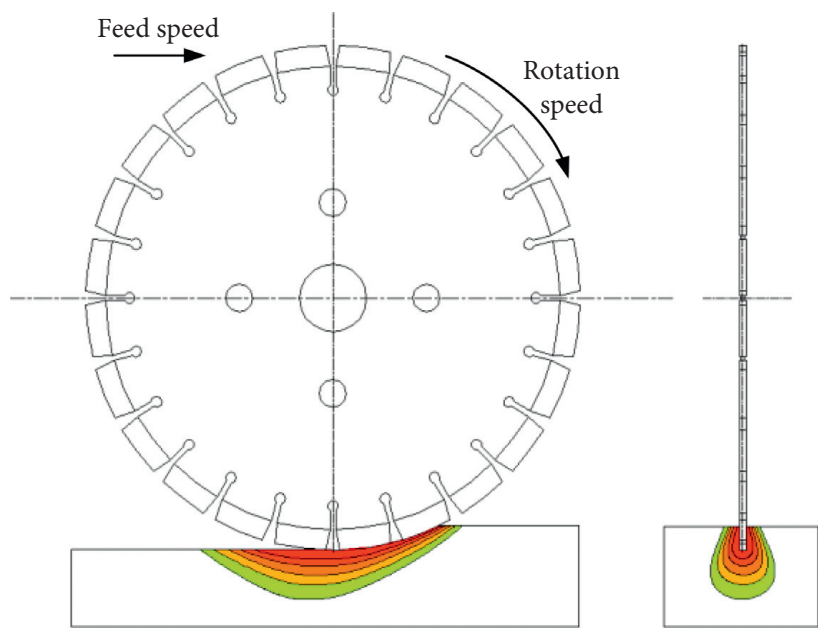

FIGURE 11: Stress distribution diagram of rock cutting with the diamond sawblade.

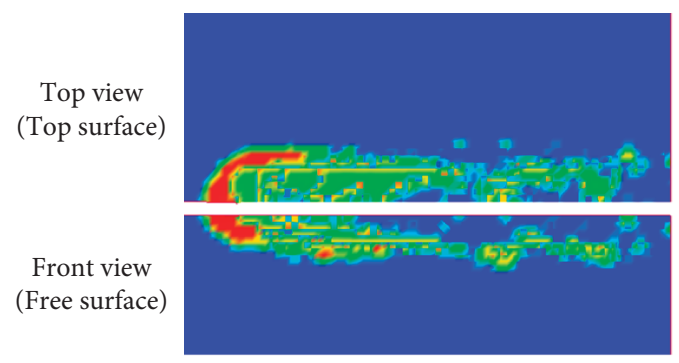

(a)

Top view (Top surface)

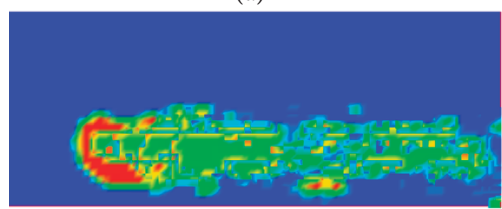

Front view (Free surface)

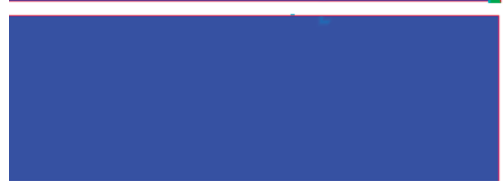

(d)
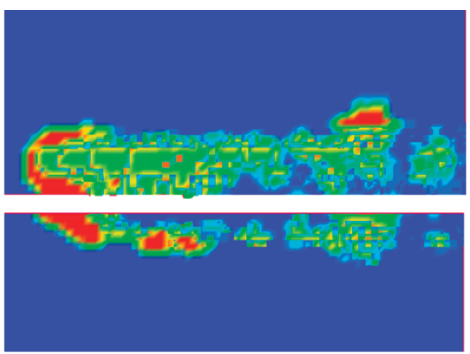

(b)
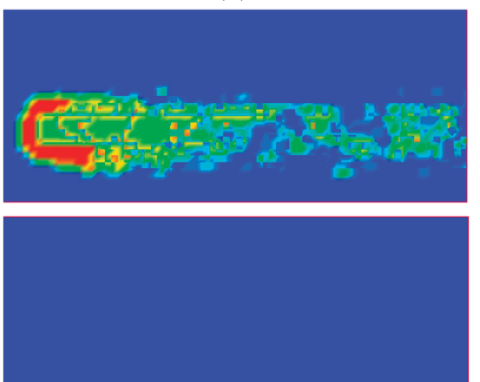

(e)

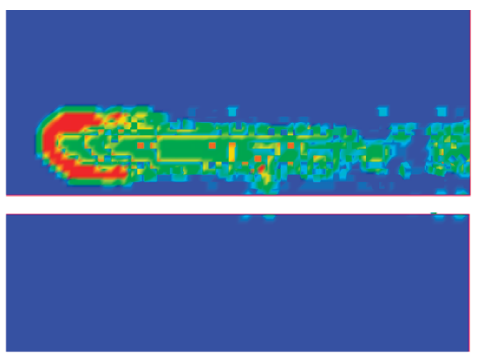

(c)
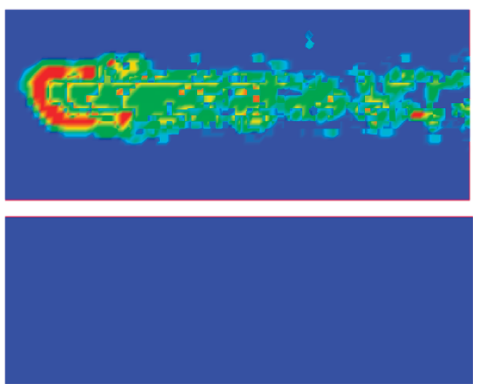

(f)

FIGURE 12: Damage nephogram of rock cut by the sawblade with different distance from rock free surface.

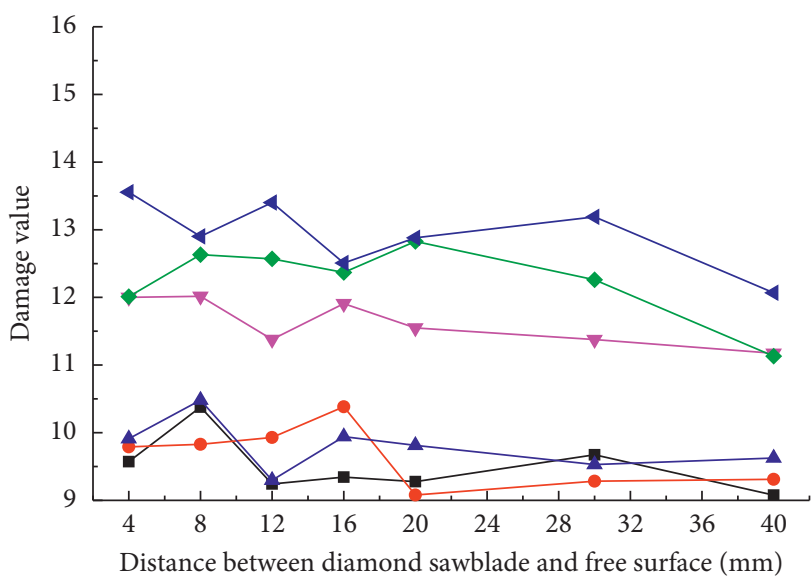

Cutting depth Feed speed

$\rightarrow-4 \mathrm{~mm} \quad 0.2 \mathrm{~m} / \mathrm{min}$

$\longrightarrow 4 \mathrm{~mm} \quad 0.3 \mathrm{~m} / \mathrm{min}$

$\longrightarrow 4 \mathrm{~mm} \quad 0.4 \mathrm{~m} / \mathrm{min}$
Cutting depth Feed speed

$\rightarrow-16 \mathrm{~mm} \quad 0.2 \mathrm{~m} / \mathrm{min}$

$\longrightarrow 16 \mathrm{~mm} 0.3 \mathrm{~m} / \mathrm{min}$

$\longleftarrow 16 \mathrm{~mm} \quad 0.4 \mathrm{~m} / \mathrm{min}$

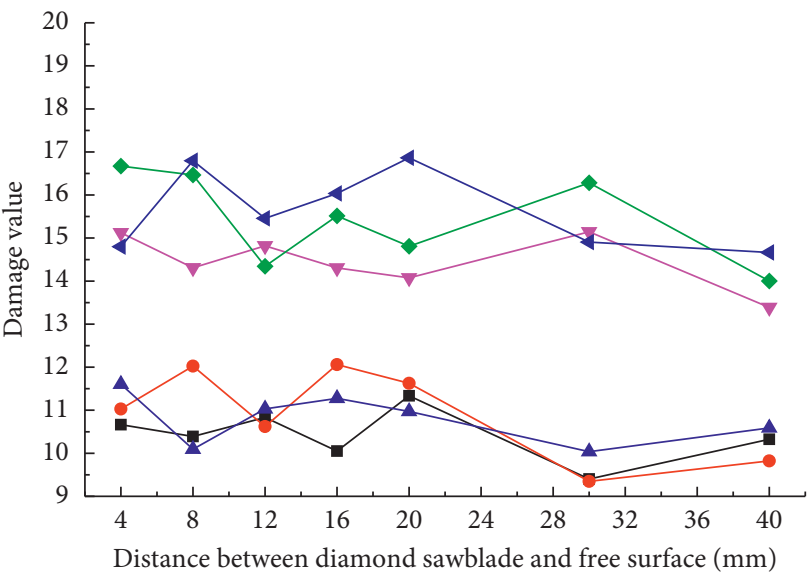

Cutting depth Feed speed

$\rightarrow-8 \mathrm{~mm} \quad 0.2 \mathrm{~m} / \mathrm{min}$

$\longrightarrow 8 \mathrm{~mm} \quad 0.3 \mathrm{~m} / \mathrm{min}$

Cutting depth Feed speed

$\neg-30 \mathrm{~mm} \quad 0.2 \mathrm{~m} / \mathrm{min}$

$\longrightarrow 30 \mathrm{~mm} 0.3 \mathrm{~m} / \mathrm{min}$

$\longrightarrow 8 \mathrm{~mm} \quad 0.4 \mathrm{~m} / \mathrm{min}$ $\longleftarrow 30 \mathrm{~mm} \quad 0.4 \mathrm{~m} / \mathrm{min}$

(b)

FIGURE 13: Variation curve of the rock damage value and distance between the sawblade and rock free surface. 
increases, and the damage decreases and disappears on the free surface.

The image recognition program quantifies the image of rock damage caused by the fixed depth cutting of the diamond sawblade, and the diamond sawblade cuts the rock with different feed speeds and different distances to the free surface. The curve of the relationship between the damage value of rock cut by the sawblade and the distance from the free surface of the sawblade is shown in Figure 13. When the sawblade cuts the rock at a certain depth, the distance from the sawblade to the free surface has a significant influence on the rock damage value. With the increase of the distance from the sawblade to the free surface, the damage value of rock decreases obviously and then tends to be stable. When the distance between the diamond sawblade and the free surface is less than $20 \mathrm{~mm}$, the rock damage value fluctuates greatly; while the distance is greater than $20 \mathrm{~mm}$, the rock damage value fluctuation tends to be stable and the fluctuation is small. At the same cutting depth, the rock damage value is positively related to the feed rate. The larger the feed rate of the sawblade is, the greater the rock damage value is; the influence of cutting depth on the rock damage value is significant, and the rock damage value increases significantly with the increase of cutting depth, significantly enhancing compared with the cutting speed.

\section{Conclusion}

Based on ANSYS/LS-DYNA, this article establishes the numerical model of rock cutting with the diamond sawblade and studies the influence of the distance between the diamond sawblade and free surface on cutting performance. In addition, it establishes an image recognition program and carries out a quantitative analysis of rock damage based on the principle of image recognition, so as to improve the accuracy of the research.

(1) In the process of the diamond sawblade cutting rock, the average cutting force, normal force, and tangential force of the sawblade rise with the increasing distance from the diamond sawblade to the free surface, but the sawblade average axial force changes on contrary. When the distance reaches $20 \mathrm{~mm}$, they begin to stabilize.

(2) The damage range of the rock free surface decreases with the rise of the distance from the diamond sawblade to the rock free surface in the diamond sawblade cutting rock process. While the distance between the diamond sawblade and the rock free surface increases to $16 \mathrm{~mm}$, the rock free surface damage disappears basically. And when the distance reaches $12 \mathrm{~mm}$, there is a relatively complete rock plate between the diamond sawblade and free surface forming.

(3) The rock damage area is affected by the diamond sawblade rotation direction in the process of the diamond sawblade cutting rock. The rock damage thickness appears in the contact area between the diamond sawblade and the rock, which is offset by a certain distance along the direction of rotation speed. When the distance increases to $20 \mathrm{~mm}$, the free surface effect on the average and free surface damage disappear basically.

(4) The image recognition method is used to quantitatively analyze the rock damage. The distance from the diamond sawblade to surface has a significant impact on the rock damage. The rock damage value decreases with the increase of the distance from the diamond sawblade to the free surface, and the damage value is positively correlated with the diamond sawblade cutting speed. The rock damage value is positively correlated with the cutting speed in the diamond sawblade cutting rock process with fixed depth.

\section{Data Availability}

The data used to support the findings of this study are included within the article.

\section{Conflicts of Interest}

The authors declare that there are no conflicts of interest.

\section{Acknowledgments}

This work was supported by the Key Research and Development Project of China (2017YFC0603000) and the Natural Science Foundation of Shandong Province (ZR2019BEE069).

\section{References}

[1] X. Xu, Y. Li, and Y. Yu, "Force ratio in the circular sawing of granites with a diamond segmented blade," Journal of $\mathrm{Ma}$ terials Processing Technology, vol. 139, no. 1-3, pp. 281-285, 2003.

[2] X. Xu, Y. Li, and S. Malkin, "Forces and energy in circular sawing and grinding of granite," Journal of Manufacturing Science and Engineering, vol. 123, no. 1, pp. 13-22, 2000.

[3] M. Yurdakul, "Effect of cutting parameters on consumed power in industrial granite cutting processes performed with the multi-disc block cutter," International Journal of Rock Mechanics and Mining Sciences, vol. 76, pp. 104-111, 2015.

[4] M. Yurdakul and H. Akdas, "Prediction of specific cutting energy for large diameter circular saws during natural stone cutting," International Journal of Rock Mechanics and Mining Sciences, vol. 53, pp. 38-44, 2012.

[5] A. Ersoy and U. Atici, "Specific energy prediction for circular diamond saw in cutting different types of rocks using multivariable linear regression analysis," Journal of Mining Science, vol. 41, no. 3, pp. 240-260, 2005.

[6] A. Güney, "Performance prediction of large-diameter circular saws based on surface hardness tests for Mugla (Turkey) marbles," Rock Mechanics and Rock Engineering, vol. 44, no. 3 , pp. 357-366, 2011.

[7] I. S. Buyuksagis, "Effect of cutting mode on the sawability of granites using segmented circular diamond sawblade," Journal of Materials Processing Technology, vol. 183, no. 2-3, pp. 399-406, 2007. 
[8] I. S. Buyuksagis and R. M. Goktan, "Investigation of marble machining performance using an instrumented block-cutter," Journal of Materials Processing Technology, vol. 169, no. 2, pp. 258-262, 2005.

[9] B. Gospodarič, B. Bučar, and G. Fajdiga, "Active vibration control of circular saw blades," European Journal of Wood and Wood Products, vol. 73, no. 2, pp. 151-158, 2015.

[10] P. Wang, P. Ge, Y. Gao, and W. Bi, "Prediction of sawing force for single-crystal silicon carbide with fixed abrasive diamond wire saw," Materials Science in Semiconductor Processing, vol. 63, pp. 25-32, 2017.

[11] W. T. Chang and L. C. Chen, "Design and experimental evaluation of a circular saw blade with self-clamped cutting inserts," International Journal of Advanced Manufacturing Technology, vol. 83, no. 1-4, pp. 365-379, 2016.

[12] G. M. Krolczyk, J. B. Krolczyk, S. Legutko, and A. Hunjet, "Effect of the disc processing technology on the vibration level of the chipper during operations," Tehnicki vjesnik-technical gazette, vol. 21, pp. 447-450, 2014.

[13] J. Konstanty, "Theoretical analysis of stone sawing with diamonds," Journal of Materials Processing Technology, vol. 123, no. 1, pp. 146-154, 2002.

[14] J. Konstanty, "Diamond bonding and matrix wear mechanisms involved in circular sawing of stone," International Diamond Review, vol. 60, pp. 22-65, 2000.

[15] A. Di Ilio and A. Togna, "A theoretical wear model for diamond tools in stone cutting," International Journal of $\mathrm{Ma}$ chine Tools and Manufacture, vol. 43, no. 11, pp. 1171-1177, 2003.

[16] X. Wei, C. Y. Wang, and Z. H. Zhou, "Study on the fuzzy ranking of granite sawability," Journal of Materials Processing Technology, vol. 139, no. 1-3, pp. 277-280, 2003.

[17] A. Ersoy, S. Buyuksagic, and U. Atici, "Wear characteristics of circular diamond saws in the cutting of different hard abrasive rocks," Wear, vol. 258, no. 9, pp. 1422-1436, 2005.

[18] X. Xu, "Study on the thermal wear of diamond segmented tools in circular sawing of granites," Tribology Letters, vol. 10, no. 4, pp. 245-250, 2001.

[19] I. S. Buyuksagis, "Effect of cutting mode on the sawability of granites using segmented circular diamond sawblade," Journal of Materials Processing Technology, vol. 183, pp. 399-406, 2006.

[20] B. Unver, "A statistical method for practical assessment of sawability of rocks," in Proceedings of ISRM International Symposium. Eurock '96, pp. 59-65, Turin, Italy, September 1996.

[21] N. Sánchez Delgado, A. Rodríguez-Rey, L. M. Suárez del Río, I. Díez Sarriá, L. Calleja, and V. G. Ruiz de Argandoña, "The influence of rock microhardness on the sawability of Pink Porrino granite (Spain)," International Journal of Rock Mechanics and Mining Sciences, vol. 42, no. 1, pp. 161-166, 2005.

[22] R. D. Peng, Y. C. Yang, P. Wang, and Y. J. Zhang, "Developments in detection of rock damage," Applied Mechanics and Materials, vol. 152-154, pp. 1018-1023, 2012.

[23] H. Xie, L. Li, R. Peng, and Y. Ju, "Energy analysis and criteria for structural failure of rocks," Journal of Rock Mechanics and Geotechnical Engineering, vol. 1, no. 1, pp. 11-20, 2009.

[24] E. D. Steffler, J. S. Epstein, and E. G. Conley, "Energy partitioning for a crack under remote shear and compression," International Journal of Fracture, vol. 120, no. 4, pp. 563-580, 2003.

[25] X. Y. Zhang, H. N. Ruan, and C. H. Jia, "Research development of the rock's damage theory," Sichuan Building Science, vol. 2, pp. 134-138, 2010.
[26] X. R. Ge, J. X. Ren, Y. B. Pu, W. Ma, and H. Sun, Microscopic and Mesoscopic Experimental Studies of Damage Mechanics of Rock and Soil, Science Press, Beijing, China, 2004.

[27] Q. Zeng, Z. Wang, L. Wan, X. Zhang, and Z. Lu, "Study on the damage of coal and rock with diamond sawblade cutting based on LS-DYNA," International Journal of Computational Materials Science and Engineering, vol. 6, no. 4, Article ID 1750026, 2018.

[28] Z. Wang, Q. Zeng, Z. Lu, L. Wan, and X. Zhang, "Numerical simulation of rock cutting with a diamond sawblade based on LS-DYNA," Mathematical Problems in Engineering, vol. 2019, pp. 1-15, Article ID 6462909, 2019. 